\title{
Frequency of Self-Reported Hip and Knee Pain in Elderly Population
}

\section{Azra Bibi', Aamir Gul Memon², Abdul Razzaque Rahimoon³, Tayyiba Zulqarnain', Marina Khan Soomro4, Shoaib Ahmed Memon ${ }^{4}$}

\author{
${ }^{1}$ Physiotherapist at City care medical center Hyderabad. \\ ${ }^{2}$ Assistant Professor, Suleman Roshan College of Physiotherapy Rehabilitation Sciences, Tando Adam \\ ${ }^{3}$ Physiotherapist at Center for Autism Rehabilitation Training Sindh \\ ${ }^{4}$ Lecturer at Abasyn Univeristy Islamabad campus. \\ 5,6 Lecturer at Suleman Roshan College of physiotherapy Rehabilitation Sciences, Tando Adam
}

Author's Contribution

1,2 Conception and design, ${ }^{3-5}$ Collection and assembly of data, ${ }^{1,3}$ Analysis and interpretation of the data, Statistical expertise, 2, 4 Drafting of Article, 1,2 Critical revision of the article for important intellectual content, Final approval and guarantor of the article

Article Info.

Received: Dec 27, 2020

Acceptance: June 11, 2021

Conflict of Interest: None

Funding Sources: None

Address of Correspondence

Dr Aamir Gul Memon

Email ld: aamir_mmn642@yahoo.com

Cite this article as: Bibi A, Memon $A G$, Rahimoon AR, Zulqarnain $T$, Soomro MK, Memon SA. Frequency of Self-Reported Hip and Knee Pain in Elderly Population. JRCRS. 2021; 9(1). 27-30-. DOl: https://dx.doi.org/10.53389/JRCRS.20 21090106 $\frac{\text { A B S T R A C T }}{\text { Background: Knee pain is a typical complaint among adults and frequently connected with }}$ general mileage from everyday exercises like strolling, bowing, standing, and lifting. Competitors who run or play sports that include bouncing or fast rotating are additionally bound to encounter knee torment and issues. However, regardless of whether a person's knee torment is brought about by maturing or injury, it very well may be a disturbance and in any event, weakening in certain conditions.

Objective: To determine the Frequency of hip and knee pain in elderly people.

Methodology: A cross-sectional survey was conducted on 150 patients, which were selected through non probability convenience sampling technique and was calculated by Rao Soft tool from Aug 2020 to Nov 2020. Data was collected from private clinics of Hyderabad and Physiotherapy OPD, Suleman Roshan Medical college hospital using standard questionnaire the Western Ontario McMaster Universities osteoarthritis index (WOMAC), and VAS scale for self-reported pain measurement. Data was analyzed using SPSS v. 21

Results: Shows that unilateral or predominantly affected knee were found $47 \%$, bilateral Knee $16 \%$, unilateral hip $20 \%$, hip bilaterally $6 \%$, both knee-hip pain reported about $11 \%$ among participants. And Patient having none or mild pain $21.3 \%$, moderate pain $26.0 \%$, severe pain $36.7 \%$, extremely severe pain $16.0 \%$. Participants having pain while performing ADLs (Activity of daily livings) reported, No Pain $60.7 \%$, Moderate Pain $33.3 \%$, worst possible pain $6.0 \%$ were found.

Conclusion: The results of this study indicate that $47 \%$ of knee joint pain were found with $36.7 \%$ severe pain and high frequent than hip joint.

Keywords: Elderly, Hip, Knee, Frequency, Self-Reported Pain

\section{Introduction}

Musculoskeletal conditions area unit predominant and their impact is inescapable. They're the foremost widely known reason for the serious end of the day torment and actual handicap, and that they influence an enormous variety of people around the globe. They primarily influence the psychosocial standing of influenced people even as their families and career. ${ }^{1}$ at any one time, $30 \%$ of American adults area unit influenced by joint pain, expanding, or restriction of movement. Walking is that the most typical method by that a personal will keep physically active. ${ }^{2}$ however, knee pain is a serious disabling downside among the foremost active part of the population i.e. the young adults. The prevalence of knee pain was reported $3.9 \%$ among children of age 9-10 years, $3.3 \%$ in the age of $10-19$ years, $25 \%$ in adults of age $18-35$ years, $28 \%$ in those older than 45 years, and about $37 \%$ in elderly aged 65 years and above. ${ }^{3}$ In Republic of Finland knee pain prevalence among young 
agers was reported to be $18.5 \% .^{2}$ In China, 39 of youngsters aged 16 years or on top of had knee pain4. Female's area unit a pair of 2.23 times additional susceptible to have Patello-femoral pain than males. ${ }^{5}$ Prevalence of anterior knee pain among ladies aged 1835 years was reported $12-13 \% .{ }^{6}$ Associate in nursing redoubled $Q$-angle of 2-3 degrees was found to be inflicting knee pain among women aged $15-23$ years. ${ }^{7} \mathrm{~A}$ sixteen years follow-up was applied upon adolescent women having idiopathic anterior knee pain, 71 women continued to possess knee pain for 20years. ${ }^{8}$ knee is that the most typical site of disorder. ${ }^{9}$ and accounts $33 \%$ of all contractile musculoskeletal problems. ${ }^{10}$

A study was conducted by M.A Cimminio, et all. Department of medical specialty, University of city Italian. Sample size was 4,456 Aged sixteen years and additional, designated form was ARC form 3,294 answerer were asked to reply. Result was joint pain was reportable by $889(27 \%)$ joint swelling was reportable $463(14 \%)$ prevalence of joint pain symptom hyperbolic age in each sex found high level of prevalence of pain and swelling within the peripheral joint normally Italian population. Prevalence was high in Italian than in China and Asian nation. ${ }^{7}$ another study was conducted by Else Odding Hens et all. Department of medicine and Biostatistics theologist University of school of medicine, Holland. The sample size was 1156 men and 1739 girls. Arbitrarily the used Health Assessment form (HAQ) result were locomotors incapacity. Lower limb operate $(20.2 \%)$ men $(31.9 \%)$ women. Hip pain was presented in $(8.3 \%)$ men $(16.6 \%)$ women knee pain in $(16.6 \%)$ women. knee pain in (12.6)men (22.31\%) girls degenerative arthritis grade hip was (14.1) men (15.9\%)women and knee( sixteen.3\%) men(29.1\%) women. ${ }^{8}$ Former study results showed that the prevalence of current pain was $59.7 \%$ and past four weeks was $74 . .5 \%$. Most commonly affected knee $3.9 \%$ and bilaterally $9.7 \%$ prevalence of pain was increase with age. ${ }^{9}$

Another result 9,957 surveyed responded, 2,207 complained of hip pain (22.2\%) 43 participants did or may never response the Question 698(15.6\%) was American state and 1,509 (27.5\%) was girls WHO have toughened knee pain presently 3,015 total people $(30.3 \%)$ 1,290 men, 1,725 girls gave a positive response.1089 suffered from daily having a solely knee pain $641(6.4 \%)$ had undergone operation and different injury associated with knee. ${ }^{10} \mathrm{~A}$ Study was conducted by J. town et al, response rate was $66.3 \%, 19.2 \%$ reportable hip pain and 32.65 participants was reportable knee pain. the share of hip and knee was reported $11.3 \%, 40.7 \%$ reportable hip and knee pain half the population were affected the unilateral pain. There was associate degree association between self-reported VAS pain with the physical operate and study. ${ }^{11} \mathrm{~A}$ study was conducted by P. Dieppe et al, it has been calculable that $7.5 \%$ of individuals was over 55 year have some knee and hip pain and incapacity related to picture taking proof of $O A$ which a pair of have severe problems. ${ }^{12}$

\section{Methodology}

A cross-sectional survey was conducted at different Physiotherapy Clinics of Hyderabad and Physiotherapy OPD, Suleman Roshan Medical college hospital. Total 150 patients, which were selected through non probability convenience sampling technique and was calculated by Rao Soft tool from Aug 2020 to Nov 2020. The participants which was below age 40years and any trauma or fractured since last 6 months history was excluded from this study. A detailed standard Questionnaire was used, contained 21 items included demographic data, mainly addressing the Western Ontario Mac Master Universities (WOMAC) index, and VAS scale was used. Patients having self-reported musculoskeletal pain. Data analysis SPSS 21.0 version. Categorical variables were expressed in terms of frequency and percentages.

\section{Results}

According to the results of self-reported pain in hip or knee that results of total of 150 participants, 83(55\%) were female and $67(45 \%)$ were male given in figure 01 . Current pain: $46.93 \%$, pain with last 6 months $16.68 \%$, current joint complaints $34.23 \%$.

Patient having unilateral or predominantly affected knee were $47 \%$, Knee Bilateral $16 \%$, hip unilateral $20 \%$, hip bilaterally $6 \%$, knee-hip pain reported $11 \%$ among participants in given table I. And Patient having none or mild pain $21.3 \%$, moderate pain $26.0 \%$, severe pain $36.7 \%$, extremely severe pain $16.0 \%$ given in table II. 
Participants having pain while performing ADLs (Activity of daily livings) reported, No Pain $60.7 \%$, Moderate Pain $33.3 \%$, worst possible pain $6.0 \%$ are given in table III.

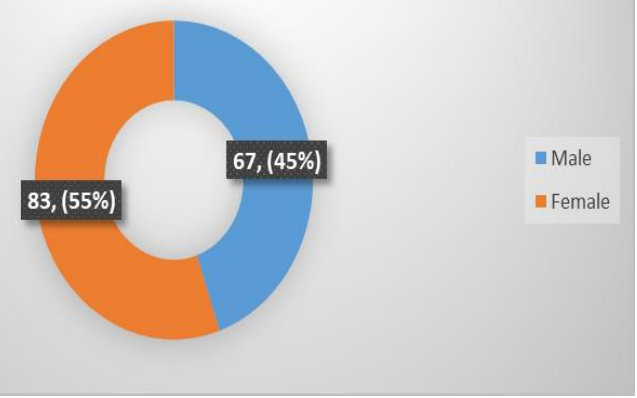

Figure 1. Gender of participants

\begin{tabular}{lr}
\hline Table I: Shows Site of Pain & \\
\hline Site of pain & Percentage \\
\hline Unilateral Knee & $47 \%$ \\
\hline Bilateral Knee & $16 \%$ \\
\hline Unilateral Hip & $20 \%$ \\
\hline Bilateral Hip & $6 \%$ \\
\hline Knee and hip both & $11 \%$ \\
\hline Total & $100 \%$ \\
\hline
\end{tabular}

\begin{tabular}{lcr}
\hline \multicolumn{3}{c}{ Table II: Shows Intensity of pain at rest } \\
\hline \multicolumn{1}{c}{ Intensity } & Frequency & Percent \\
\hline None or mild pain & 32 & 21.3 \\
\hline Moderate pain & 39 & 26.0 \\
\hline Severe pain & 55 & 36.7 \\
\hline $\begin{array}{l}\text { Extremely Severe } \\
\text { pain }\end{array}$ & 24 & 16.0 \\
\hline Total & $\mathbf{1 5 0}$ & $\mathbf{1 0 0 . 0}$ \\
\hline
\end{tabular}

\begin{tabular}{lcr}
\hline $\begin{array}{l}\text { Table III: Shows Severity of pain while performing daily } \\
\text { living activities (ADLs) }\end{array}$ & Frequency & Percent \\
\hline \multicolumn{1}{c}{ Intensity } & 91 & 60.7 \\
\hline Light pain & 50 & 33.3 \\
\hline Moderate pain & 9 & 6.0 \\
\hline Worst pain & 150 & 100.0 \\
\hline Total &
\end{tabular}

Discussion

Previous studies have shown variable level of knee joint pain prevalence, like Roush et al (2012), reportable the prevalence of knee pain in females at a mean age of 24.74 years, to be $12-13 \%{ }^{6}$

In another study, out of $40.2 \%$ females with respectively pain, over half of them $(53.9 \%)$ had a grievance of bilateral knee pain wherever as $24.2 \%$ and $21.8 \%$ reportable right and left knee pain severally. Roush also reportable knee pain to be $13 \%$ in right knee and $12 \%$ in left knee among female population of eighteen to 35 years. ${ }^{7}$

Another past study was directed in 2013 by Ulrich Thiem et tired Federal Republic of Germany within the Department of medicine, faculty of Bochum, Marien clinic Herne, that outcomes demonstrated that commonness of current torment was $59.7 \%$ and up to date weeks was $74.5 \%$. Most commonly influenced knee $30.9 \%$ and severally respectively $9.7 \%$ predominance of pain was expanded with age. ${ }^{13}$

In an earlier study of subjects aged 79-85 year, painful knees attributed to OA were ascertained in thirty eighth of females and thirteen of males. In 574 individuals aged 55 , knee pain was reportable by $13 \%$ of females and $8 \%$ of males. ${ }^{14}$

A past report was directed by Jordi Miro et tired the branch of neuroscience. The predominance of pain was $73.5 \%$ higher in feminine than males, who elaborated torment $94.2 \%$ were experiencing in progress torment the mean score of VAS was $4.8 \%$ out of $10.35 .5 \%$ of member elaborated impediment in ADLs (movement of everyday living) in light of pain. ${ }^{15}$

Another investigation was led by Elaine Thomas et all at the division of essential Care science analysis focus, selfrevealed question was finished with joint pain space of recent weeks with torment electric resistance of movement of day by day living $71.3 \%$ react rate was accounted for recent week torment generality was $72.4 \%$ higher in female than male. $12.5 \%$ of public having torment in additional than one territory of the body. Most normal space was knee, hip and ankle pain 3.8\% public had issue with the movement of everyday living. ${ }^{16}$

A recent examination showed that lower limb work $(20.2 \%)$ men $(31.9 \%)$ ladies. Hip pain was given in (8.3\%) men, (16.6\%) ladies knee pain in (16.6\%) ladies. knee torment in (12.6) men, $(22.31 \%)$ female arthritis score hip was (14.1) men (15.9\%) ladies and knee (16.3\%) men (29.1\%) ladies. ${ }^{17}$

In our survey we found that patient having unilateral or $20 \%$ affected knee were $47 \%$, Knee Bilateral 16\%, hip unilateral $20 \%$, hip bilaterally $6 \%$, knee-hip pain reportable $11 \%$ among participants, a patient having none or mild pain $21.3 \%$, moderate pain $26.0 \%$, severe pain 
$36.7 \%$, extremely severe pain $16.0 \%$ was reportable. Participants having pain whereas reported ADLs (Activity of daily livings) reported, No Pain $60.7 \%$, Moderate Pain $33.3 \%$, worst doable pain $6.0 \%$ were found.

\section{Conclusion}

The results of this study indicate that $47 \%$ of knee joint pain were found with $36.7 \%$ severe pain and high frequent than hip joint.

\section{References}

1. Woolf $A D$, Akesson $K$. Understanding the burden of musculoskeletal conditions. The burden is huge and not reflected in national health priorities. BMJ. 2001;322:107980

2. White DK, Keysor JJ, Neogi T, Felson DT, LaValley M, Gross KD, et al. When it hurts, a positive attitude may help: association of positive affect with daily walking in knee osteoarthritis. Results from a multicenter longitudinal cohort study. Arthritis care \& research. 2012;64(9):131219.

3. Wang S-Y, Olson-Kellogg B, Shamliyan TA, Choi J-Y, Ramakrishnan R, Kane RL. Physical Therapy Interventions for Knee Pain Secondary to OsteoarthritisA Systematic Review. Ann Intern Med. 2012;157(9):632-44.

4. Zeng QY, Chen R, Xiao ZY, Huang S-B, Liu Y, Xu JC, et al. Low prevalence of knee and back pain in southeast China; the Shantou COPCORD study. J Rheumatol 2004;31(12):2439-43.

5. Boling M, Padua D, Marshall S, Guskiewicz K, Pyne S, Beutler A. Gender differences in the incidence and prevalence of patellofemoral pain syndrome. Scand J Med Sci Sports 2010;20(5):725-30.

6. Witonski D. Anterior knee pain syndrome. Int Orthop 1999;23(6):341-44.

7. Roush JR, Bay RC. Prevalence of anterior knee pain in 18-35 year-old females. Int J Sports Phy Ther 2012;7(4):396.
8. Nimon G, Murray D, Sandow M, Goodfellow J. Natural history of anterior knee pain: a 14-to 20-year follow-up of nonoperative management. $\mathrm{J}$ Pediatr Orthop 1998;18(1):118-22.

9. O'Reilly S, Muir K, Doherty M. Knee pain and disability in the Nottingham community: association with poor health status and psychological distress. $\mathrm{Br} \mathrm{J}$ Rheumatol 1998;37(8):870-73.

10. Calmbach WL, Hutchens M. Evaluation of Patients Presenting with Knee Pain: Part I. History, Physical Examination, Radiographs, and Laboratory Tests. Am Fam Physician 2003;68(5):907-11. Blackburn TA, Craig E. Knee Anatomy A Brief Review. Phys Ther 1980;60(12):1556-60.

12. Bolgla LA, Boling MC. An update for the conservative management of patellofemoral pain syndrome: a systematic review of the literature from 2000 to 2010. Int J Sports Phys Ther 2011;6(2):112.

13. Miro J, Paredes $S$, Rull M, Queral R, Miralles R, Nieto R, Huguet $A$, et al. Pain in older adults: a prevalence study in the Mediterranean region of Catalonia. Eur J Pain.2007; 11(1): 83-92

14. Bagge E, Bjelle A, Eden S, Svanborg A. Osteoarthritis in the elderly: clinical and radiological findings in 79 and 85 year olds. Ann Rheum Dis 1991:535-9

15. Bergenudd $H$, Nilsson $B$, Lindgarde F. Knee pain in middle age and its relationship to occupational workload and psychosocial factors. Clin Orthop 1989; 245:210-5.

16. Thiem U, Lamsfuß R, Günther S, Schumacher J, Bäker C, Endres HG, Zacher J, Burmester GR, Pientka L. Prevalence of self-reported pain, joint complaints and knee or hip complaints in adults aged $\geq 40$ years: a crosssectional survey in Herne, Germany. PLoS One. 2013;8(4):e60753.

17. Thomas E, Peat G, Harris L, Wilkie R, Croft PR. The prevalence of pain and pain interference in a general population of older adults: cross-sectional findings from the North Staffordshire Osteoarthritis. 2004;110(1-2):361-8. 